\title{
A criação de uma identidade para o historiador $\mathrm{e}$ para seus escritos
}

\author{
Diogo da Silva Roiz ${ }^{I}$ \\ Universidade Federal do Paraná
}

HARTOG, F. Os antigos, o passado e o presente. Brasília: Ed. UnB, 2003. Trad. de José Otávio Guimarães.

$\mathrm{O}$ historiador francês François Hartog, especialista em historiografia antiga e moderna, já é conhecido pelo público brasileiro (especializado) por seus livros O espelho de Heródoto (publicado em 1999), A história de Homero a Santo Agostinho (editado em 2001) e O século XIX e a história: o caso Fustel de Coulanges (impresso em 2003). Seu novo livro Os antigos, o passado e o presente é uma coletânea de artigos anteriormente publicados em livros e em revistas especializadas, na década de 1990 (com exceção do último, que é de 1982, impresso em um número especial da revista Annales sobre história antiga).

Foi o professor José Otávio Guimarães responsável pela seleção, organização e parte da tradução dos originais, e a quem François Hartog fez um generoso agradecimento no final de seu prefácio à coletânea. Em função da origem dos ensaios e das condições de sua organização, esse livro difere dos anteriormente publicados pelo autor (dois estudos monográficos, um sobre Heródoto e outro sobre Fustel de Coulanges, e uma antologia de textos de autores gregos e romanos sobre o conceito de história na Antigüidade Clássica e Tardia). Ainda que o livro não seja um estudo monográfico, muitos fatores contribuem para que os textos não sejam vistos como um conjunto aleatório. Em primeiro lugar, são estudos de história intelectual e historiografia antiga, nos quais, conforme o autor indicou em seu prefácio, foram reunidos em torno de três termos, que se desdobram no conjunto dos ensaios: os antigos (os gregos, mas também os romanos), o passado e o presente (os deles, mas também os nossos). Em segundo lugar, avaliam quando a História,

\footnotetext{
${ }^{1}$ Doutorando em História pela UFPR. Mestre em História pela Unesp/Franca. Professor do Departamento de História nos cursos de História e de Ciências Sociais da Universidade Estadual de Mato Grosso do Sul (UEMS), na unidade de Amambaí. Endereço para correspondencias: Rua José Luiz Sampaio Ferraz, 1133, Vila Gisele, Amambaí, MS, 79990-000 (diogosr@yahoo.com.br).
} 
de uma vivência circunscrita num processo de vários agires humanos no tempo, passou também a ter valor testemunhal no relato escrito, embora circunstancial (às vezes até efềmero) e fragmentário, que almejava, com base em interpretações, criar uma "identidade coletiva" às sociedades de outrora, como ainda mantê-la nas sociedades presentes, por meio da análise dos indícios do passado (recente ou remoto). Desse modo, cotejaram-se os paralelos entre passado e presente, visualizados e elaborados por gregos e romanos, e quais paralelos visualizavam-se entre aquele passado, da Antigüidade Clássica (e Tardia), e o nosso presente, o das sociedades contemporâneas.

O livro divide-se em duas partes complementares, intituladas $O$ s antigos diante deles mesmos e Nós e os antigos, com quatro capítulos cada uma. Na primeira parte, por meio da trajetória de historiadores (como Hecateu de Mileto, Heródoto de Helicarnasso, Helânico de Lesbos, Políbio, Tucídides, Dionísio de Helicarnasso, Catão, Tito Lívio, Cícero e Fábio Píctor) e suas obras, na Antigüidade Clássica, empreende uma análise do surgimento do ofício de historiador - com seus dilemas sobre a coleta e interpretação das fontes, a veracidade e precisão de seu discurso, sua tensão entre a prova e a retórica e sua função social e política na sociedade -, e suas relações com a Cidade-Estado. Na segunda parte, volta-se com maior precisão para as maneiras como a sociedade contemporânea se relaciona, aproxima-se e distancia-se das sociedades grega e romana de outrora, a partir de estudos sobre "os fundamentos gregos da idéia de Europa", "o confronto (que se fez e se faz) com os antigos", a recepção de autores e obras, e o lugar em que hoje (1982) se encontra(ria)m os estudos de história (e historiografia) antiga nas universidades francesas.

Com base nesse rápido panorama, almeja-se, nas próximas linhas, analisar com detalhes, pelo menos alguns pontos da obra. Como foi dito, François Hartog procurou estudar a "formação da idéia de autor", projetada em quem escreve a obra, e definida de forma mais precisa "na imagem subjetiva do historiador", até então pouco usual, já que mais importante era a obra e não quem a escrevia. Assim, não foi por acaso que François Hartog iniciou sua argumentação dizendo que: "se a história, ou melhor, sua escrita, começou na Mesopotâmia com a monarquia de Akkard (2270-2083 a.C.), primeira a unificar o país sob uma autoridade única e a utilizar escribas para escrever sua história", para propor em seguida uma questão: qual seria então a originalidade dos gregos? Para tal questão, responde: 
A criação de uma identidade para o historiador e para seus escritos

Diogo da Silva Roiz

[...] com Heródoto justamente que aparece o historiador como figura 'subjetiva'. Sem estar diretamente ligado a um poder político, sem estar por este comissionado, Heródoto, desde a abertura, desde as primeiras palavras, marca, recorta, reivindica a narrativa que começa pela inscrição de um nome próprio: 0 seu, no genitivo ("De Heródoto de Helicarnasso, eis a historíe"), como já havia feito antes dele Hecateu de Mileto e como faria depois dele Tucídides de Atenas; ambos, todavia, tanto Tucídides quanto Hecateu, recorreram ao nominativo. Heródoto, por sua vez, era o autor de seu logos, e era esse logos que, diante de outros ou contra eles, vinha estabelecer sua autoridade. Mas esse novo lugar de saber, reivindicado desde o início [talvez até inspirando-se na forma como os filósofos gregos estabeleciam sua autoridade perante a obra escrita], era ao mesmo tempo algo a ser inteiramente construído. Existe nesse caso uma distância razoável com relação às historiografias orientais. Os gregos foram mais os inventores do historiador que da história (HARTOG, 2003, p. 13-4).

Embora não obtivesse naquela época o mesmo reconhecimento e autoridade que a Filosofia, mantendo-se mais como um gênero do que como uma disciplina, a História, ou mais precisamente sua escrita, com aqueles autores estabeleceria, mesmo parcialmente, o papel do historiador. Entendendo-se, desde já, que o autor designou por figura do historiador " [...] os traços e os gestos inaugurais, as configurações epistemológicas, assim como os relatos que tornaram possível e sustentaram a primeira narrativa histórica. É no esboço dessa figura que me detenho aqui"' (Idem, p. 14). Por isso, procurou inquirir como Heródoto teria lido aquela tradição oral deixada na forma escrita de epopéia por Homero, quando escreveu suas investigações. Por isso também, observou se haveria algum senso de historicidade entre a Iliada e a Odisséia, além da idéia de "eterno presente" na narrativa épica. 
Desse modo, o autor observa que:

De Demódoco [discurso épico] a Heródoto [discurso histórico], a passagem não foi nem imediata nem obrigatória, mas simplesmente possível. Em seu face a face com Ulisses, a figura de Demódoco permite, por um momento, que se perceba uma outra, a que, bem mais tarde, um certo Heródoto daria nome e fala próprios: a figura do historiador, com a operação historiográfica que acompanha seu nascimento. Mas entre a fala épica e o discurso historiográfico, a Odisséia, que cantava a impossibilidade da epopéia, contava a descoberta fascinante e dolorosa da historicidade (Idem, p. 33).

Seu argumento se adensa ainda mais quando passa a discorrer mais detalhadamente a obra de Heródoto no capítulo seguinte. Em suas palavras:

Tal como o historiógrafo moderno, que, comissionado por um príncipe, procurava ver os eventos com os olhos de seu patrão, ocupando, ao menos por algum tempo e em termos narrativos, "sua posição", Heródoto tencionava ver como Apolo adotava seu ponto de vista, mas, para fazê-lo, tinha de expressá-lo ou convertêlo em palavras ou sentenças, vale dizer, em uma narrativa [...]. De certo modo, procedeu como o historiador moderno, que organiza sua narrativa como se estivesse realmente partindo do passado para chegar ao presente, utilizando com maior ou menor cautela ou sofisticação a conveniente explicação [retrospectiva dos acontecimentos] (Idem, p. 49).

Em seguida, de Heródoto passa a Tucídides (que pensou uma história política grega) e depois a Cícero (que a via como fornecedora de exemplos e mestra da vida), indicando que o "esclarecimento do passado requer a intervenção constante do historiador para descobrir os fatos e raciocinar sobre os indícios. 
O presente, em contrapartida, parece falar ou dar-se a ver por si mesmo, e o historiador se apaga. Tucídides restringiu o campo da história ao presente, $\mathrm{e}$ seu objeto, à história política da Grécia" (Idem, p. 59).

Na seqüência, destaca a obra de Dionísio de Helicarnasso, diferenciando-o de Heródoto e Tucídides, e o comparando com eles. Para ele, da:

[...] ortodoxa declaração de historiador, começando por delimitar cronologicamente $o$ assunto, com a diferença de que, lá onde o historiador começava por estabelecer, de um modo ou de outro, um corte (Heródoto separando o tempo dos deuses e o tempo dos homens, ou Tucídides demonstrando em sua "arqueologia" que do passado não se podia escrever a historía), Dionísio reivindica a continuidade: dos mýthoi à história e a história a partir dos mýthoi (Idem, p. 75).

Apoiando-se em Fábio Píctor e Homero para estudar os rituais romanos, Dionísio teria, segundo o autor, avançado nas pesquisas e no córpus documental, pois, além "da genealogia, da etimologia, da invocação de 'testemunhos', o investigador, para convencer-se e persuadir, lançava mão de todas as marcas, traços, restos, objetos [...] ainda visíveis [e a] isso se junta[ria]m, enfim, os testemunhos fornecidos pelas festas, pelos rituais e pelos sacrifícios" (Idem, p.78). Demonstrou, ao contrário de o que se afirmava naquele momento, que os romanos não seriam etruscos (nem troianos), "pois são gregos, filhos de gregos; e se são troianos, ainda são, ou já eram, gregos"(Idem, p. 94), queria, com isso, indicar como surgiu ou se criou uma identidade romana.

Como foi dito, na segunda parte, o autor volta-se mais para como gregos e romanos percebiam seu passado e seu presente, e como nós hoje estabelecemos certas relações de continuidade (e também de descontinuidade) entre aquele passado e nosso presente. Ainda que sua atenção não esteja mais diretamente ligada à questão de como se definiu o ofício de historiador na Antigüidade Clássica, François Hartog não a deixa de lado, pois, ao se preocupar com como teriam se elaborado alguns "fundamentos gregos de [uma] idéia de Europa", ao indicar os possíveis "confrontos [que do Renascimento para cá] se estabeleceriam com o antigo", não deixa de lado a tensão sempre persistente, que surge entre quem escreve e o escrito. 


\section{HưmANAS}

Desse modo se pode dizer que o autor passaria sua análise, que estava inicialmente centrada na criação da figura subjetiva do historiador, para as tensões e interpretações que sua escrita da História ou de histórias desencadearia no tempo (passado para o presente e do presente para o passado, quando olhado retrospectivamente). Portanto, o programa pensado pelo autor no início da década de 1980 (e esboçado em seu último ensaio) para a História e, particularmente, a escrita da história e da historiografia antiga, parcelada nas universidades francesas (como ainda em universidades de outros países) entre a História Medieval, a História Moderna e a História Contemporânea, mantêm-se ainda hoje bastante atual. Para ele:

História antiga e história: sem dúvida, historiador algum retomaria hoje por iniciativa própria as previsões de Langlois e Seignobos a propósito do esgotamento, por conta da falta de documentos, do trabalho histórico relativo a certos períodos da antiguidade e aquelas a respeito do inevitável "refluxo" para os períodos modernos. Primeiro, porque existem documentos novos (além do mais, a própria noção de documento se expandiu), e depois, sobretudo, porque ninguém pensa mais que o trabalho histórico se resuma à crítica exaustiva do documento, nem que o livro de história ideal seja a simples listagem de documentos que se oferecem em sua pura verdade (Idem, p. 192).

Portanto, essa sugestiva e bem efetuada organização de ensaios de François Hartog muito contribui para não apenas se visualizar bem o conjunto da obra desse autor, mas, ainda, compreender a complexidade de seus estudos e a forma como eles se articulam, entre a historiografia antiga e moderna, na história da definição da identidade do historiador e de seus escritos. 